Sefarad Vol 56, Fasc. 2 (1996)

\title{
EL ASCENSO SOCIOPOLÍTICO DE LOS JUDEO- CONVERSOS EN LA CASTILLA DEL SIGLO XVI EL EJEMPLO DE LA FAMILIA BELTRÁN EN SORIA
}

\author{
MÁXIMO DIAGO HERNANDO \\ CSIC. Barcelona
}

En los trabajos de investigación dedicados a la historia de los judíos y judeoconversos castellanos durante la Baja Edad Media y temprana Edad Moderna la ciudad de Soria ha de ser necesariamente tenida en cuenta, dada la importancia de la comunidad judía allí asentada durante el siglo XV', y la abundancia relativa de judeoconversos constatable en este mismo núcleo urbal cant. i el siglo $\mathrm{XV}$ como en el XVI ${ }^{2}$. Para analizar el proceso de integración y

\footnotetext{
${ }^{1}$ Para determinar la importancia de la judería de Soria en relación con otras juderías del reino de Castilla en el siglo XV vid. M. A. LADERo QueSADA, "Las juderias de Castilla según algunos servicios fiscales del siglo XV», Sefarad 31 (1971) 249-264. Entre otras obras que dedican atención a la judería soriana se pueden destacar F. CANTERA BURGos, "Juderías medievales en la provincia de Soria», en Homenaje a fray Justo Pérez de Urbel, Silos 1976, 445-482; D. Gonzalo MAeso, «La judería de Soria y el rabino José Albo", MEAH 20 (1971) 119-142; ÍDEM, "Aportaciones a la historia de la judería de Soria», Celtiberia 56 (1978) 153-168. Entre los varios artículos en los que E. CANTERA Montenegro hace referencias a los judíos de Soria cabría destacar: «Pleitos de usura en la diócesis de Osma en el último tercio del siglo XV", AEM 12 (1982) 597-622; "Conflictos entre el concejo y la aljama de los judíos de Soria en el último tercio del siglo XV", AEM 13 (1983) 583-593; "El apartamiento de judíos y mudéjares en las diócesis de Osma y Sigüenza a fines del siglo XV", AEM 17 (1987) 501-510; véase también M. DiaGo, «Judios y judeoconversos en Soria en el siglo XV", Celtiberia 83 (1992) 225-253. Al final del texto desarrollamos las abreviaturas utilizadas en este artículo.

${ }^{2}$ Sobre los judeoconversos sorianos del siglo XV porporcionamos noticias en $\mathrm{M}$. Diago, "Judíos y judeoconversos" y en ÍDEM, Estructuras de poder en Soria a fines de la Edad Media, Valladolid 1993. Sobre los judeoconversos sorianos del siglo XVI tratamos en M. DiaGo, "Los judeoconversos en Soria después de 1492", Sefarad 51 (1991) 259-298. Uno de los primeros autores que abordó esta cuestión fue $F$. Cantera Burgos, "Conversos y judaizantes en la provincia de Soria (con especial referencia a los Laínez)», Revista de Dialectología y Tradiciones Populares 32 (1976) $87-102$.
} 
ascenso sociopolítico de las familias judeoconversas castellanas, Soria ofrece por otra parte ejemplos muy ilustrativos, hasta el punto de que en algunos casos se pueden considerar paradigmáticos; a uno de ellos, el de la familia de los Ramírez de Lucena, ya hemos dedicado nuestra atención en un trabajo monográfico ${ }^{3}$.

El ascenso de esta familia tuvo lugar en el siglo $\mathrm{XV}$ y se vio afectado por todos los factores adversos que determinaron el destino de las familias judeoconversas castellanas de ese siglo, entre los que habría que destacar el de la persistencia de la posibilidad de mantener contactos con judíos, que según algunos autores fue un factor decisivo para que se mantuviese la desconfianza hacia la sinceridad de las conversiones. En concreto este problema afectó muy seriamente a la familia Lucena, puesto que algunos de sus más destacados miembros continuaron profesando la religión judía sin por ello abandonar los contactos con sus parientes judeoconversos, hecho que dio pie a que se llegase a denunciar a varios de estos últimos por prácticas de criptojudaísmo ${ }^{4}$.

Para complementar, pues, nuestro trabajo sobre los Ramírez de Lucena, que ilustra un proceso de integración y ascenso en última instancia truncado, hemos juzgado de interés reconstruir otro proceso que se desarrolló en unas circunstancias muy distintas a las del siglo $\mathrm{XV}$, como fueron las que se impusieron después de la expulsión de los judíos del reino de Castilla en 1492, proceso que tuvo un desenlace mucho más afortunado. En concreto estuvo protagonizado por una familia, la de los Beltrán, convertida después de 1492, y que por lo tanto nunca se vio afectada por los inconvenientes que para los Ramírez de Lucena se derivaron de la convivencia con parientes y amigos judíos. Sus miembros, muy poco tiempo después de su conversión al cristianismo, intentaron por todos los medios alardear de su adhesión a la nueva fe, fundando capillas y dotando capellanías. Y no parece que tropezasen con muchos inconvenientes a la hora de convencer a sus conciudadanos de la sinceridad de su conversión, pese a que su condición de recaudadores de impuestos y mercaderes rápidamente enriquecidos bien hubiera podido despertar rencores que derivasen en la presentación de denuncias ante la Inquisición. En efecto no nos consta que en ninguna ocasión el

\footnotetext{
${ }^{3}$ M. DiAGo, «El protonotario Lucena en su entorno sociopolítico. Nuevos datos sobre su biografia», Sefarad 53 (1993) 249-272.

${ }^{4}$ Ibid.
} 
tribunal inquisitorial procediese contra miembros de esta familia cuyos orígenes judíos estaban tan cercanos. $\mathrm{Y}$ al mismo tiempo no nos deja de sorprender que muchos de sus miembros terminasen incorporándose a cabildos catedralicios y órdenes militares, instituciones en las que, según el punto de vista más difundido, los estatutos de limpieza de sangre habían terminado impidiendo no sólo la entrada de herejes sino también de cualquiera que tuviese antecesores judíos o musulmanes, en aplicación de un principio que muchos han calificado de "racista" s. Su integración en la sociedad cristiana fue, pues, total, hasta el punto de que en el siglo XVII habían conseguido ya borrar todo recuerdo de su origen judío, como demuestran las interminables series de declaraciones de testigos en las pruebas de acceso a las órdenes militares donde se repetía machaconamente que distintos descendientes de Vicen Bienveniste, que se convirtió al cristianismo después de 1492, eran cristianos viejos sin ninguna mancha de raza judía en su sangre ${ }^{6}$.

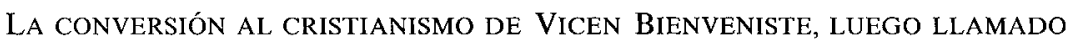
NiCOLAO BELTRÁN

No es mucho lo que hemos conseguido averiguar sobre la identidad del judío soriano que, poco después de marchar a Portugal en 1492, decidió regresar a Castilla convertido al cristianismo con el nombre de Nicolao Beltrán ${ }^{7}$. De hecho en la documentación con-

\footnotetext{
${ }^{5}$ Entre otras obras de interés sobre esta cuestión hay que destacar, A. A. SiCRofF, Los estatutos de limpieza de sangre. Controversias entre los siglos XV y XVI, Madrid 1985; J. EDwARDS, «Race and religion in fifteenth and sixteenth century Spain: the purity of blood statutes revisited", en Proceedings of the Tenth World Congress of Jewish Studies. The History of the Jewish People, Jerusalén 1990, 159-166; Y. M. LAMBERT-GORGES, «Le bréviaire du bon enquêteur, ou trois siècles d'information sur les candidats à l'habit des ordres militaires», Mélanges de la Casa de Velázquez 18 (1982) $165-198$.

6 Véase, por ejemplo, el voluminoso expediente para la entrada en Calatrava de Juan Zapata, en AHN, OOMM, Calatrava, exp. 2.864. Contiene múltiples diligencias realizadas en Soria y otras partes de Castilla para determinar el posible origen judío de los Beltranes. No se encontró ninguna prueba documental y todos los testigos fueron unánimes al declarar que eran cristianos viejos.

7 Las referencias a la estancia en Portugal del que luego fue Nicolao Beltrán son varias. Muy clarificadora resulta a este respecto la declaración del sastre judeoconverso de Almazán, Fernán Pérez, quien en 1505 reconoció que siendo criado de Nicolao Beltrán marchó con él a Portugal en 1492, y al poco regresó a Ciudad Rodrigo para
} 
sultada le hemos encontrado nombrado de muy diversas maneras: unas veces simplemente Bienveniste, otras Don Yuça Bienveniste, y con mucha más frecuencia Vicen Bienveniste ${ }^{8}$. Entrar a determinar su grado de parentesco con otros judíos sorianos que se llamaron de una forma parecida resulta sumamente arriesgado, a falta de referencias precisas que proporcionen pistas seguras; pero no hay que descartar tampoco a priori que pudiese estar emparentado con alguno de ellos, entre los que se contaron destacados hombres de negocios.

Por lo que a él se refiere, no faltan pruebas documentales que demuestran que ya desarrolló una cierta actividad de hombre de negocios durante la etapa de su vida en que fue judío. En efecto consta, por ejemplo, que a raíz de abandonar Castilla en 1492, en cumplimiento del decreto de expulsión, traspasó a los judeoconversos Luis de Alcalá y Fernán Núñez Coronel las cantidades de dinero que le debían unos mercaderes burgaleses por ciertas lanas que les había vendido ${ }^{9}$. El hecho de que Fernán Núñez Coronel fuera un converso de recientísima fecha, ya que había adoptado la fe cristiana apremiado por los Reyes Católicos poco antes de abandonar el resto de los judíos el reino, explicaría su elección por Vicen Bienveniste para traspasarle sus deudas, en la confianza de que luego le haría llegar el dinero a Portugal, si no en moneda, ya que estaba prohibida su saca, al menos por medio de letras de cambio ${ }^{10}$.

convertirse allí al cristianismo, dejando en Portugal a su amo. Vid. C. Carrete PARrondo - C. Fraile Conde, Fontes Iudaeorum Regni Castellae IV. Los judeoconversos de Almazán 1501-1505. Origen familiar de los Laínez, Salamanca 1987, pág. 55.

8 Véase, por ejemplo, AGS, RGS, III-1498, fol. 116. En este documento se hace constar primeramente que Nicolao Beltrán cuando era judío se llamaba Bienveniste, aunque más adelante se indica qùe su nombre era entonces Don Yuça Bienveniste. Puede verse un documento, entre otros, donde se le identifica como Vicen Bienveniste en AGS, RGS, V-1493, fol. 249.

9 AGS, RGS, IV-1493, fol. 87 y V-1493, fol. 249. Sobre el papel de los judíos en el comercio de la lana en Soria, vid. M. DIAGO, "El comercio de la lana en Soria en época de los Reyes Católicos», Celtiberia 77-78 (1989) 25-76.

${ }^{10}$ Sobre las figuras de Fernán Núñez Coronel, rabí Mayr Melamed hasta su conversión, y Luis de Alcalá, como miembros principales de una compañía de arrendadores al servicio de los Reyes Católicos vid. C. Álvarez García, «Los judíos y la hacienda real bajo el reinado de los Reyes Católicos. Una compañía de arrendadores de rentas reales", en Las tres culturas en la Corona de Castilla y los sefardies, Valladolid 1990, 87-126. 
Por otra parte consta que fueron muchos los judíos emigrados a Portugal que dejaron encomendada la gestión de su hacienda en Castilla a este acaudalado judeoconverso segoviano, encargándole en particular que cobrase por ellos las cantidades que se les adeudaban, aunque parece que entre éstos fueron mayoritarios los que tenían cargo de cobrar rentas de la monarquía, en muchos casos quizás como subarrendadores del propio Fernán Núñez Coronel " Por ello entra dentro de lo posible que Vicen Bienveniste perteneciese también a este grupo de arrendadores y que incluso su tardía conversión al cristianismo fuese el resultado de las presiones ejercidas por Fernán Núñez Coronel sobre varios de los arrendadores judíos castellanos exiliados en Portugal para que regresasen convertidos a Castilla ${ }^{12}$. Y, en efecto, Vicen Bienveniste, una vez convertido al cristianismo con el nombre de Nicolao Beltrán consta que sirvió a los Reyes Católicos en varias tareas de recaudación de rentas ${ }^{13}$.

Por lo demás, otros documentos prueban que Fernán Núñez Coronel se sirvió de Nicolao Beltrán, cuando todavía era judío y marchó con los demás judíos a Portugal, para que en el vecino reino le sirviese de enlace e efectos de cumplir con los compromisos adquiridos con ciertos judíos de quienes era acreedor. Y así nos lo demuestra por ejemplo el caso de Simuel Abenxuxen, médico del marqués de Villena, quien había prestado cierta cantidad de dinero a Fernán Núñez Coronel, el cual, cuando Abenxuxen decidió mar-

"C. Álvarez García, Art. cit. pág. 122, publica allí un memorial presentado por Fernán Núñez Coronel a los Reyes Católicos en el que manifiesta que se había informado a los monarcas «que algunos judíos me dexaron a mí encomendado mucha hasienda e la yo he cobrado de sus debdas so color que eran de las rentas de V. A.». Proporcionamos noticias inéditas basadas en documentos de AGS, RGS sobre traspasos de deudas a Fernán Núñez Coronel efectuados por judios sorianos emigrados a Portugal, que fucron arrendadores de rentas, con condición de que se les transfiriese el dinero a Portugal, en nuestra comunicación "Los hombres de negocios judíos en Soria en las vísperas de la expulsión", presentada al Congreso Internacional sobre Judíos y Conversos en la Historia (Ribadavia oct. 1991); permanece inédita, pues no ha sido incluida en la reciente edición de las actas del congreso.

12 C. Álvarez García, Art. cit. En el referido memorial Fernán Núñez Coronel manifestó que había trabajado mucho junto con sus hijos "por convertyr a algunos de aquellos arrendadores e a muchos dellos tornamos e traximos convertidos».

13 Véase AGS, RGS, XII-1497, donde se indica que Nicolao Beltrán había sido receptor en Molina de Aragón y su partido en 1493-1494. En AGS, Contaduría Mayor de Cuentas, $1^{\text {a }}$. época, leg. 67, Nicolao Beltrán figura como receptor de lo encabezado del obispado de Osma de 1505, y su hijo Antonio Beltrán en varios años a partir de 1512 . 
char a Portugal en 1492, entregó a Bienveniste, judío vecino de Soria que luego se llamaría Nicolao Beltrán, una cédula de cambio por la que le ordenaba que al presentarse en Portugal pagase a Abenxuxen 1.253 ducados ${ }^{14}$.

Finalmente, las relaciones entre Nicolao Beltrán y Fernán Núñez Coronel continuaron después de que el primero regresara convertido a Castilla, puesto que en 1495 este último y sus hijos le vendieron la mitad del oficio del recaudamiento y receptoría del servicio y montazgo, del que en 1489 los reyes habían hecho merced a Yuce Abravanel y que, tras diversas vicisitudes, había terminado por llegar a manos suyas ${ }^{15}$.

Por consiguiente y teniendo en cuenta todos estos hechos, parece bastante probable que la conversión al cristianismo de Vicen Bienveniste estuviese dictada por el deseo de no desvincularse del mundo de los negocios en Castilla, en el que se encontraba muy bien situado dadas sus estrechas relaciones con financieros de primera fila, como eran los Núñez Coronel de Segovia. Algunos indicios sugieren que, a pesar de la propia irregularidad de la conversión,

\footnotetext{
14 Véase en AGS, RGS, III-1498, fol. 116 la carta de emplazamiento a Nicolao Beltrán, que inserta una cédula dirigida al licenciado Polanco, alcalde de Casa y Corte, ordenando a Nicolao Beltrán que pagase los ducados que debía a Gabriel Enríquez, físico del marqués de Villena. Dado que en 1497 se decretó el bautismo forzoso de todos los judíos residentes en Portugal, entendemos que fue entonces cuando Simuel Abenxuxen adoptó el nombre cristiano de Gabriel Enríquez, y aprovechó para reclamar la cantidad que en su momento no le había pagado Nicolao Beltrán. De hecho, a partir de 1498 proliferan en el Registro General del Sello solicitudes de judíos de origen castellano convertidos forzosamente al cristianismo en Portugal para que se les pagasen deudas que se les debían desde el momento de la expulsión. Se ofrecen más detalles en nuestra comunicación «Los hombres de negocios judíos» citada en la nota 11; ahi damos cuenta de cómo varios judíos sorianos arrendadores de rentas, al tomar el camino del exilio optaron por dar «algunos dineros a cambios para que se los diesen en Portugal» a diversos individuos entre los que figuraban Fernán Núñez Coronel y su hijo Pedro Núñez, Nicolao Beltrán y varios judeoconversos de Burgos. En una situación semejante a la de Simuel Abenxuxen (Gabriel Enríquez), se vio también Lope Jiménez, judeoconverso vecino de Portugal, quien en 1499 reclamó 306 ducados que Nicolao Beltrán le debía por letra de cambio. AGS, RGS, V-1499.

${ }^{15}$ Véanse referencias a las vicisitudes del oficio en C. Álvarez García, Art. cit. págs. 98 y 104-105. El precio que Nicolao Beltrán tuvo que pagar por la mitad del oficio fue de un millón de maravedís y al poco tiempo de efectuarse la venta debió seguir pleito en Chancillería contra Francisco Fernández Coronel, hijo de Fernán Núñez Coronel, ya difunto, por querer éste recuperar la referida mitad alegando que su padre había efectuado la venta «por temor». AChV, RE, C. 176 (I-1503).
} 
realizada pocos meses después de haber elegido el exilio portugués frente a la forzada adopción de la religión cristiana, los propios Reyes Católicos la aplaudieron e incluso la gratificaron. En concreto así cabe interpretar la concesión en Barcelona, el 30 de abril de 1493, del privilegio de hidalguía a Nicolao Beltrán y a toda su descendencia, que sin duda representó una manifestación de buena voluntad de los reyes hacia un individuo en el que quizás apreciaban sobre todo su valía como financiero y el estar apadrinado por otros financieros todavía más poderosos ${ }^{16}$.

\section{ACTITUD HACIA LA IGLESIA Y LA RELIGIÓN CRISTIANA}

Como fue muy frecuente entre las familias judeoconversas castellanas tanto del siglo XV como del XVI, Nicolao Beltrán quiso dar prueba de su sincera adhesión a su nueva fe cristiana, destinando a uno de sus cuatro hijos a la Iglesia. El elegido fue Alonso Beltrán, quien consta que en 1519 residía en Roma, donde se había convertido en scriptor apostólico ${ }^{17}$, y luego regresó a su tierra natal para ocupar la dignidad de maestrescuela de la catedral de Osma ${ }^{18}$. Su carrera sentó precedentes en la familia, y así por ejemplo su hermano mayor, Antonio Beltrán, destinó al menos dos de su cuatro hijos varones a la carrera eclesiástica, de forma que el mayor de ellos, Francisco Beltrán de Ribera, llegó a ser deán de Soria, y el otro, Juan de Ribera, fue enviado a la Universidad de Salamanca y luego a Roma, donde profesaría votos religiosos, a los que luego sin embargo debió de terminar renunciando ${ }^{19}$. $\mathrm{Y}$ este mismo Antonio

\footnotetext{
${ }^{16}$ Puede verse la confirmación del privilegio otorgado en Barcelona el 30 abril 1493 y ratificado en Madrid el 12 nov. 1494, hecha por Felipe II en Madrid el 22 dic. 1563, a petición de Nicolao Beltrán de Ribera y Antonio Beltrán de Ribera, nietos de Nicolao Beltrán, en RAH, Salazar y Castro, M-112, hojas 167-177.

${ }^{17}$ Véase el Archivo de la iglesia concatedral de San Pedro de Soria, libro 63, registro de 17 junio 1519, donde se hace constar que a Alonso Beltrán, scriptor apostólico residente en Roma, León X en 1519 le proveyó de una canonjía, que antes era vicaría, en la iglesia de San Pedro de Soria.

18 Ya figura identificado como maestrescuela de Osma en la escritura de fundación de la capilla de los Beltranes en la iglesia de San Esteban de Soria, fechada el 9 enero 1529. Referencia a esta escritura en AHN, OOMM, Calatrava, Exp. 2864.

${ }^{19}$ En AHPS, C. 3519-7 se recogen bastantes noticias sobre pagos efectuados por Antonio Beltrán a su hijo Juan de Ribera durante los cinco años (entre 1537 y 1541) que permaneció en el estudio de Salamanca y después en sus estancias en Zaragoza,
} 
Beltrán destinó a varias de sus numerosas hijas a la vida contemplativa del convento, llevado seguramente por convicciones religiosas y por el deseo de dejar bien puesta de manifiesto su sincera adhesión a la religión católica, pero tal vez también forzado por factores de índole económica ante la imposibilidad de dotar convenientemente a sus seis hijas para conseguirles «buenos» matrimonios, es decir con personas de condición sociopolítica elevada, como lo fueron los elegidos como maridos de sus dos hijas mayores ${ }^{20}$.

Además de destinar hijos e hijas a la Iglesia, los primeros Beltranes hicieron notorios alardes en la construcción y dotación de capillas, destinadas para enterramientos familiares, y en la fundación de capellanías. En concreto Nicolao Beltrán hizo construir la actual capilla de San Nicolás de Bari en la iglesia del monasterio de San Francisco de Soria, que durante el siglo XV había sido el lugar preferido por las familias de la oligarquía soriana e incluso por algunas de la alta nobleza de la región para hacer construir en él sus capillas funerarias ${ }^{21}$. Al hacer construir esta capilla, afortunada-

Barcelona y Roma. Entre las muchas partidas de gastos ocasionados durante su permanencia en Roma figura una referente al pago por una bula «para absolverle de la frailía».

20 Antonio Beltrán y María de Ribera tuvieron seis hijas. A Catalina la casaron con el caballero soriano Rodrigo Morales de Albornoz, perteneciente a una influyente familia de la oligarquía soriana a la que habían pertenecido miembros del Consejo Real como el licenciado Diego Morales. Al concertarse su matrimonio hacia 1529 se le concedió una dote de $1.600 .000 \mathrm{mrs}$. a los que luego se añadieron otros bienes. Su otra hermana, Francisca de Ribera, fue casada con Pedro Hurtado de Mendoza, señor de Hinojosa de la Sierra, y perteneciente a una rama cadete de una familia de la alta nobleza castellana. No hemos determinado el importe de la dote pero también debió de ser elevada. Otras dos hijas, Ana de Ribera e Isabel Beltrán, profesaron como monjas en el monasterio de Santiago el Zebedeo de Sigüenza. Se concedió a cada una una dote de 500 ducados, e igual cantidad se prometió a su hermana Elena de Ribera cuando entró en el monasterio de Santa Clara de Soria. No hemos llegado a determinar cuál fue el destino de su sexta hermana, María. Las diferencias entre la dote de Catalina y las dotes de sus hermanas monjas demuestran hasta qué punto la entrada en los monasterios resultaba más barata para los padres, aunque ciertamente Antonio Beltrán tuvo que pleitear con el monasterio de Santiago de Sigüenza, que exigía una mayor participación en la herencia familiar para Ana de Ribera e Isabel Beltrán. Tomamos las noticias de AHPS, C. 3519-7.

${ }^{21}$ Allí se hicieron enterrar por ejemplo el señor de Cameros, Carlos de Arellano, y su mujer Constanza Sarmiento, y el conde de Castro, señor de Gormaz. Las referencias a capillas y enterramientos de familias de la oligarquía soriana son múltiples en documentación en su mayor parte inédita, que hemos manejado para nuestra tesis doctoral y otros posteriores trabajos de investigación. 
mente conservada hasta la actualidad cuando casi todas las demás perecieron en un incendio, el reciente converso que era Nicolao Beltrán ya trataba, pues, de ponerse a la altura de las más encumbradas familias de la nobleza soriana, procurando echar tierra sobre su pasado judío. Por ello también, además de financiar los gastos de la construcción de la capilla, dejó al monasterio franciscano una renta anual de 3.365 mrs. situados sobre un juro, para que se cantasen varias misas cada año por su alma y las de sus parientes difuntos ${ }^{22}$. A esta donación se sumaron luego las de su esposa Isabel Beltrán, su hija Inés Beltrán y su nuera Isabel Coronel, que dejaron al monasterio de San Francisco de Soria rentas perpetuas de $2.000,2.500$ y 3.000 mrs. anuales respectivamente, con el cargo de que se celebrase una serie de oficios litúrgicos cada año en la capilla de los Beltranes ${ }^{23}$.

Años más tarde, por su parte, otros dos hijos de Nicolao Beltrán, su primogénito Antonio y Alonso, maestrescuela de Osma, se comprometieron a edificar a sus expensas una capilla mayor dentro de la iglesia de San Esteban, de la que eran parroquianos ellos y otros muchos judeoconversos sorianos, que sería destinada para enterramientos de la familia ${ }^{24}$. Y años más tarde, en el testamento que otorgaron conjuntamente, Antonio Beltrán y su esposa María de Ribera dispusieron la fundación en la referida iglesia de una capellanía perpetua, adscrita al mayorazgo, con la condición de que el clérigo que la tuviese a su cargo no dispusiese de ningún otro beneficio ni capellanía ${ }^{25}$.

\footnotetext{
${ }^{22}$ La escritura de fundación de la capilla al parecer fue otorgada el 7 mayo 1505 ante Gonzalo Gómez de San Clemente. Proporciona la noticia J. M. ${ }^{\text {a MarTínez }}$ Frías, El gótico en Soria. Arquitectura y escultura monumental, Soria 1980, págs. 256257. Las noticias documentales sobre el pago de los $3.365 \mathrm{mrs}$. situados sobre un juro son múltiples. Puede verse, por ejemplo, la numerosa documentación referente a los Beltranes custodiada en AChV, P.C. Zarandona y Balboa, F. envoltorio 139; y las referencias indirectas contenidas en AHN, OOMM, Calatrava, exp. 2864.

23 Según referencias tomadas del libro de caja del monasterio de San Francisco, de las que se da cuenta en AHN, OOMM, Calatrava, exp. 2864. Presumimos que Isabel Coronel era la esposa de Hernando Beltrán, uno de los cuatro hijos de Nicolao.

${ }^{24}$ La escritura de concierto entre Antonio y Alonso Beltrán de un lado, y el cura y parroquianos de San Esteban de otro, sobre construcción de la capilla mayor se otorgaría el 9 enero 1529, según consta en AHN, OOMM, Calatrava, exp. 2864. Aquí también se describen la capilla y las tumbas tal como se encontraban en el siglo XVII. No hay restos de esta iglesia en la actualidad. Sobre el alto número de judeoconversos entre los parroquianos de San Esteban a principios del siglo XVI llamamos la atención en M. DIAGO, «Los judeoconversos en Soria», págs. 268-269.

${ }^{25}$ Copia de este testamento, fechado en Soria el 1 dic. 1546, en AHPS, C. 3519-7.
} 
En suma, pues, aunque estas disposiciones sobre fundaciones de capillas y capellanías no difirieron sustancialmente de las que se pueden encontrar en las escrituras notariales de otras muchas familias acaudaladas de Soria y del conjunto de Castilla durante el siglo XVI, que fue de relativa prosperidad en todo el reino, no se puede dejar de advertir un cierto afán de ostentación en estos primeros representantes de la familia Beltrán, que en muy pocos años hicieron construir dos capillas y multiplicaron las fundaciones de capellanías, generalmente bien dotadas ${ }^{26}$.

Determinar si junto al afán de ostentación también tuvieron su papel los escrúpulos de conciencia a la hora de mover a algunos miembros de la familia a multiplicar en sus testamentos las disposiciones piadosas es algo que queda prácticamente fuera del alcance del historiador; pero si nos atenemos a la letra del testamento de Antonio Beltrán y María de Ribera podemos presumir que sí, ya que contiene constantes referencias a los muchos tratos y negocios que había tenido el primero durante su vida, y a la consiguiente necesidad de descargar las conciencias de ambos, que habían participado de los provechos económicos derivados de dichos negocios, por medio de disposiciones piadosas ${ }^{27}$.

No hay motivos, pues, para dudar de la sinceridad de la conversión al cristianismo de los Beltranes sorianos, que cumplieron escrupulosamente con todas las convenciones que en la época conllevaba la profesión de la religión católica y manifestaron incluso una preocupación por el peligro que para su salvación eterna podía conllevar la dedicación a ciertas actividades económicas consideradas por las autoridades eclesiásticas como sospechosas de propiciar el enriquecimiento ilícito. Hasta qué punto en estas manifestaciones

\footnotetext{
${ }^{26}$ A este respecto hay que advertir que Antonio Beltrán y María de Ribera, además de disponer la fundación de la capellanía perpetua de San Esteban, adscrita al mayorazgo, establecieron otras cuatro capellanías por las ánimas del purgatorio en los monasterios de San Francisco, La Merced y Nuestra Señora de Gracia, y en la iglesia parroquial del Espino, dotando cada una con $5.000 \mathrm{mrs}$.

27 Además de las fundaciones de capellanías ya referidas, entre las disposiciones piadosas contenidas en el testamento se pueden destacar las siguientes: misas en los lugares sagrados de Roma; gastar 1.300 ducados en obras pías, limosnas y sacrificios; compra de cuatro «bulas de compusición», para redención de pecados; establecimiento de un arca de la misericordia con 200 fanegas de trigo en Ledesma, aldea de la Tierra de Soria donde los Beltranes eran principales terratenientes; y fundación de una alhóndiga en la villa de Tejado, de la que eran señores, para la cual donaron dos yuntas de heredad.
} 
había convencionalismo social y hasta qué punto profunda convicción personal es algo que ningún historiador puede decidir con absoluta seguridad. Pero el hecho constatable es que los Beltranes en muy poco tiempo consiguieron adaptarse plenamente al modo de vida propio de los cristianos viejos de la Castilla del siglo XVI, codeándose incluso con inquisidores generales, como Hernando de Valdés, a quien Antonio Beltrán sirvió como recaudador de sus rentas en el obispado de Sigüenza ${ }^{28}$.

LOS JUDEOCONVERSOS EN EL MUNDO DE LOS NEGOCIOS: ANTONIO BELTRÁN

El hijo primogénito de Nicolao Beltrán, Antonio, debió de nacer hacia 1486, de forma que apenas contaría seis años de edad cuando sus padres decidieron marchar a Portugal, y al igual que sus otros tres hermanos recibiría el bautismo en muy temprana edad, por lo que en consecuencia la asimilación de la religión cristiana debió de resultar mucho más fácil en su caso que en el de sus progenitores.

De los cuatros hijos de Nicolao, nos consta que fue él, Antonio, quien más siguió en la línea de dedicación profesional marcada por su padre. Fue un hombre con una enorme diversidad de intereses en el mundo de los negocios, que por un lado continuó activo en terrenos en que ya había estado presente su padre, como por ejemplo el del arrendamiento de rentas de la monarquía o el comercio de lanas, y por otro se adentró en nuevos ámbitos de actividad en los que su audacia y buena suerte le permitieron cosechar importantes beneficios y acumular una gran fortuna.

Como arrendador de rentas de la monarquía no llegó a alcanzar la categoría de figura de primera fila, de forma que sólo lo encontramos como fiador de algunos arrendadores importantes ${ }^{29}$ y como

${ }^{28}$ Sobre Hernando de Valdés vid. J. L. González Novalín, El Inquisidor General Fernando de Valdés (1483-1568), Oviedo 1968-1971. Tomó posesión como obispo de Sigüenza el 17 enero 1540 y el 27 agosto 1546 fue preconizado arzobispo de Sevilla. Antonio Beltrán trabajó a su servicio como recaudador de las rentas de la mesa episcopal de Sigüenza durante 6 años, entre 1540 y 1545. El nombramiento de Valdés como inquisidor general tuvo lugar el 20 enero 1547. Desconocemos si en esta etapa Antonio Beltrán continuó manteniendo relaciones de negocios con él.

${ }^{29}$ Fue por ejemplo fiador de Pedro González de León, arrendador de las salinas de Atienza en los años 1517-1519. AGS, EMR, Hojas e Informaciones, leg. 577-1². 
receptor de rentas encabezadas en el obispado de Osma ${ }^{30}$. No obstante, a diferencia de su padre, consta que esta actividad la complementó con la del arrendamiento de importantes rentas eclesiásticas, como fue por ejemplo la renta de la mesa episcopal de Sigüenza, que tuvo a su cargo durante seis años, entre 1540 y 1545 , permitiéndole manejar importantes cantidades de dinero y probablemente también de cereal, que sin duda utilizaría en operaciones especulativas ${ }^{31}$.

Por lo que se refiere a su actividad como mercader de lanas parece que también fue mucho más ambiciosa que la de su padre, puesto que numerosos indicios sugieren que llegó a aventurarse en negocios de exportación a Flandes ${ }^{32}$, en los que muy raramente participaron mercaderes sorianos, relegados casi siempre a desempeñar el papel de intermediarios al servicio de mercaderes exportadores, que eran durante el siglo XVI mayoritariamente burgaleses ${ }^{33}$.

Probablemente fue esta tarea de exportador de lanas la que más contribuyó a ponerle en contacto con las ferias de Medina del Campo, en las que desarrolló una intensa actividad; pero con posterioridad también debió de verse atraído por otros muchos de los negocios que se llevaban a cabo en esta villa castellana en el siglo $\mathrm{XVI}$. Y así lo sugieren varias de las noticias contenidas en el inventa-

${ }^{30}$ Varios años a partir de 1512, según consta en AGS, Contaduría Mayor de Cuentas, 1. ${ }^{a}$ época, leg. 67.

31 AHPS, C. 3519-7. Contiene la documentación referente a un pleito sobre reparto de bienes entre herederos de Antonio Beltrán y de su esposa María de Ribera. Se hace constar que el importe anual de las rentas correspondientes al obispo de Sigüenza que Antonio Beltrán tenía que recaudar ascendía a 7.224.080,5 mrs. y que en conjunto la cantidad transferida por él al obispo Hernando Valdés, que luego fue trasladado a Sevilla, por el total de los seis años ascendió a $43.344 .483 \mathrm{mrs}$. El documento no aporta información sobre el margen de beneficios obtenido por Antonio Beltrán de su gestión al servicio del obispo.

32 Cuando en 1516 se tomaron declaraciones a testigos sobre la solvencia económica de Antonio Beltrán, presentado como fiador por el arrendador de las salinas de Atienza, varios declararon que era un hombre muy rico que tenía fama de poseer más de 30.000 ducados «en dinero y en sacas de lana que envía a Flandes" (AGS, EMR, Hojas e Informaciones, leg. 577-1 ${ }^{\circ}$ ). En el inventario post mortem realizado en 1547 a raíz de la muerte de la mujer de Antonio Beltrán, María de Ribera, figuran varias referencias a cantidades debidas por distintas personas avecindadas o estantes en Flandes. Por ejemplo un tal Juan de Bilbao de Flandes debía por una partida $3.424 .900 \mathrm{mrs}$. y por otra 2.683.958 mrs. Véase este inventario en AHPS, C. 3519-7.

${ }^{33}$ Desarrollamos esta cuestión en M. DIAGo, "El papel de la ciudad de Soria como centro del comercio lanero en el siglo XVI», Chronica Nova [en prensa]. 
rio de las cantidades que se le debían en el año 1547, a raíz de la muerte de su esposa, en el que figuran como deudores individuos de Valencia e incluso de Lyon y de Roma ${ }^{34}$. Lamentablemente esta fuente documental no indica qué tipo de negocios habían dado lugar a que le debiesen estas cantidades vecinos de tan lejanas ciudades, aunque parece poco probable que se tratase de la venta de lanas, ya que este producto nunca se negoció desde Soria con mercaderes valencianos o franceses de la zona de Lyon, sino que se exportó mayoritariamente a Flandes, y en menor cantidad a ciudades italianas como Florencia, pero nunca a Roma. Muy probablemente debieron de ser negocios estrictamente financieros los que llevaron a Antonio Beltrán a relacionarse con valencianos e italianos y franceses, entre otros extranjeros, y cabe incluso presumir que su actividad como gestor de rentas eclesiásticas, como las correspondientes al obispo de Sigüenza, contribuiría decisivamente a familiarizarle con los negocios de transferencia de dinero a través de letras y otros instrumentos de crédito, de los que se sirvieron profusamente los encargados de canalizar hacia la ciudad de Roma las prestaciones debidas al Papa por todo el orbe católico.

El hecho de que el obispo de Sigüenza, Hernando de Valdés, estuviese un tiempo en Flandes, a donde acudió en 1520, entrando allí en contacto con el emperador Carlos $\mathrm{V}$, que le apoyó decididamente en su próspera carrera política, da por otra parte pie a plantear la hipótesis de que Antonio Beltrán, quien ya en la década de 1510 es identificado como exportador de lanas a Flandes, entrase entonces en contacto con este singular individuo en territorio flamenco. $Y$ esta vinculación pudo ser la que llevase al propio Antonio Beltrán a entrar a su vez en contacto con el emperador, quien aparece incluido en la lista de acreedores del año 1547, debiendo la cantidad de 90.937 mrs. de un juro que Antonio Beltrán había comprado en su nombre al tesorero Alonso Gutiérrez ${ }^{35}$. En cualquier caso consta que en 1547 la escribanía mayor de rentas del obispado de Osma formaba parte del patrimonio de Antonio Beltrán, y,

\footnotetext{
${ }^{34}$ Por ejemplo un tal Sancho de Anda, de Valencia, le debía 1.212.500 mrs., y Juan y Antonio de Reynaldo, también de Valencia, le debían $727.500 \mathrm{mrs}$. Por su parte Antonio Nonbiso Bonbises, de León, le debía $1.068 .000 \mathrm{mrs}$. Creemos más probable que, por el nombre, este último pueda referirse a la ciudad francesa de Lyon antes que a la española.

${ }^{35}$ AHPS, C. 3519-7, inventario de bienes de 29 dic. 1547.
} 
aunque no se puede descartar que adquiriese el oficio por compra, es también probable que lo obtuviese como merced gracias a sus contactos en la corte o en premio a servicios de tipo financiero prestados al emperador o a personas de su círculo, como pudiera ser el propio Hernando Valdés.

Por lo demás entre los acreedores de Antonio Beltrán figuran también representantes de la alta nobleza de la región soriana, como el conde de Monteagudo, de manera que cabe presumir que éste desarrolló una notoria actividad como financiero y prestamista en el más alto nivel, la cual quizás en un futuro próximo pueda llegar a ser reconstruida con mayor detalle a través de la consulta de protocolos notariales de Medina del Campo.

El talante de hombre de negocios especulador propio de Antonio Beltrán queda puesto de manifiesto por otra parte en otras muchas de sus actuaciones, entre las que podríamos destacar una singular operación de compra y reventa de un rebaño ovino trashumante de 2.000 cabezas con su posesión en La Serena, que él consiguió adquirir a 9 reales por cabeza y revendió al poco tiempo a razón de 12 reales por cabeza ${ }^{36}$.

Gracias a todas esas actividades y a otras muchas que no podremos conocer nunca en detalle por falta de fuentes documentales suficientes, Antonio Beltrán consiguió incrementar considerablemente la fortuna heredada de sus padres, que ya era cuantiosa en el contexto soriano de la época. En 1516 ya se le atribuía un caudal y crédito de más de 30.000 ducados, cantidad sumamente elevada para un individuo muy joven, que rondaba los 30 años ${ }^{37}$. A lo largo de toda la primera mitad del XVI realizó importantes inversiones en la compra de señoríos de vasallos y tierras de labranza, que consiguieron pronto ponerle a la altura de las principales familias de la oligarquía soriana. Una operación de enorme envergadura fue la compra del señorío de la villa de Tejado, realizada a Alonso de Mendoza, hijo del conde de Monteagudo, por una cantidad que no hemos llegado a determinar, a la que luego se tuvieron que sumar $1.200 .000 \mathrm{mrs}$. que costó adquirir de la hacienda regia las alcabalas y tercias de la villa. Otras operaciones importantes se centraron en la compra de tierras de labranza en distintas aldeas de la Tierra de

\footnotetext{
${ }^{36}$ AChV, P.C. Taboada F. envoltorio 146-10.

37 Según declaraciones de testigos en AGS, EMR, Hojas e Informaciones, leg. 577-1‥
} 
Soria, que le permitieron convertirse en señor de más de cincuenta yuntas de heredad, además de prados, herrenales y otros bienes rústicos. Por su parte en la propia ciudad de Soria, además de hacer construir unas suntuosas casas principales, se convirtió en propietario de otras muchas casas y mesones en distintos barrios. Las inversiones en compra de juros a la hacienda regia también tuvieron bastante importancia y aseguraron una regular fuente de ingresos a la familia durante todo el siglo XVI. Y por fin las operaciones de préstamo en sus distintas variantes, tanto a miembros de familias de la nobleza como a campesinos necesitados, también drenaron importantes cantidades de capital, que en contrapartida proporcionaron rentas anuales en dinero o en especie de muy distinta envergadura ${ }^{38}$.

EL ACCESO AL EJERCICIO DEL PODER LOCAL: REGIMIENTOS PARA LOS DOS HIJOS DE ANTONIO BELTRÁN

A pesar de que Antonio Beltrán llegó a convertirse en uno de los hombres más ricos de la ciudad de Soria y alcanzó incluso la siempre envidiada categoría de señor de vasallos, no deja de llamar la atención que nunca ocupase ningún oficio de gobierno importante, permaneciendo de hecho excluido del grupo oligárquico soriano, que en la primera mitad del siglo XVI comprendía un muy reducido número de familias de caballeros hidalgos, los cuales se repartían los seis regimientos disponibles y otros oficios de rango superior, como eran las procuraciones de Cortes o las fieldades de la Tierra, entre otros ${ }^{39}$.

\footnotetext{
${ }^{38}$ Hay numerosos datos sobre el proceso de constitución de la hacienda de Antonio Beltrán, a partir de lo que heredó de sus padres, en AChV, P.C. Zarandona y Balboa, F. envoltorio 139. También presenta extraordinario interés el inventario de bienes realizado el 29 dic. 1547, a raíz de la muerte de María de Ribera, que además de en el citado fondo documental se puede consultar en AHPS, C. 3519-7. Lamentablemente este inventario no va acompañado de la correspondiente tasación, de gran utilidad para evaluar el montante total de la hacienda y la importancia relativa de los distintos componentes. En AHN, OOMM, Calatrava, exp. 2864, consta que la cuenta y reparto de los bienes que quedaron a la muerte de Antonio Beltrán se realizó ante el escribano de Soria, Francisco Pérez del Águila, el 29 abril 1568. No hemos conseguido sin embargo localizar su protocolo.

${ }^{39}$ M. Diago, Estructuras de poder, págs. 293 y ss. e ÍdEM, "Caballeros y ganaderos. Evolución del perfil socioeconómico de la oligarquía soriana en los siglos XV y XVI», Hispania 184 (1993) 451-496, 492-494.
} 
Para acceder al desempeño de todos estos oficios constituía un requisito indispensable la pertenencia a alguno de los doce linajes de caballeros hijosdalgo de la ciudad de Soria y, en principio, los Beltranes estaban excluidos de ellos por su propio origen judío, aunque la obtención del privilegio de hidalguía de los Reyes Católicos ya les abrió una vía de acceso, puesto que estaba admitido que un hidalgo que casase con doncella de alguno de los linajes pudiese ser recibido como miembro en el linaje de su mujer ${ }^{39}$. Antonio Beltrán no cumplió sin embargo con este requisito, ya que su mujer María de Ribera no era soriana, sino que procedía al parecer de Burgos, y en efecto no nos consta que fuese formalmente admitido en alguno. de los doce linajes sorianos, aunque no faltaban precedentes de personas que habían sido admitidas sin cumplir con el requisito de casar con doncella de linaje ${ }^{40}$.

En cualquier caso si él no se atrevió a dar este paso, sí lo hizo, viviendo él todavía, su hijo primogénito Nicolao Beltrán de Ribera, quien en 1543 ya había accedido al regimiento soriano por el linaje de Don Vela ${ }^{41}$. No hemos podido determinar la fecha exacta en que Nicolao se convirtió en uno de los seis regidores que gobernaban Soria en la primera mitad del XVI, pero teniendo en cuenta que fue bautizado en 1517, es seguro que su ascenso al desempeño de tan apetecido ofício se produjo cuando todavía era muy joven, quizás con apenas 20 años cumplidos ${ }^{42}$. Dado por otra parte que nos

\footnotetext{
40 M. DiAgo, «Aportación al estudio de las estructuras familiares de la nobleza urbana en la Castilla bajomedieval. Los doce linajes de Soria. Siglos XIII-XVI», Studia Historica: Historia Medieval 10 (1992) 47-72.

41 Un ejemplo significativo nos lo ofrece el arrendador judeoconverso Juan Ramírez de Lucena, padre del protonotario; vid. M. DIAGo, «El protonotario Lucena», pág. 253. Ver también otros ejemplos en M. DiAgo, «Aportación al estudio de las estructuras familiares", págs. 61 y ss.

${ }^{42}$ Cuando en 1543 se incrementó el número de oficios de regidores sorianos de seis a doce, Nicolao Beltrán de Ribera figura entre los seis regidores del número antiguo, pudiéndose deducir por exclusión que había sido designado por el linaje de Don Vela, que se turnaba en la provisión de regidores con el de San Llorente. Vid. M. DiAGo, "Caballeros y ganaderos". Los historiadores de los linajes sorianos no aportan noticias sobre cómo tuvo lugar su entrada en el linaje Don Vela; M. Martel sólo menciona la entrada en este linaje de su hermano Antonio Beltrán de Ribera; vid. M. MARTEL, Canto tercero de «La Numantina» y su comento: de la fundación de Soria y origen de los doce linajes, Madrid 1968, pág. 83. En otro lugar este mismo autor indica que los Beltranes pertenecían al linaje de San Llorente, pero hay que advertir que los caballeros con este apellido que formaron parte de este linaje nada tienen que ver con la familia de judeoconversos que aquí estamos analizando.
} 
consta que su esposa fue Juana de Palafox, hija del noble aragonés Rodrigo de Palafox, señor de Ariza ${ }^{43}$, no pudo entrar en el linaje de Don Vela a raíz de su matrimonio.

Entra dentro de lo posible por lo tanto que ya Antonio Beltrán, amparándose en la influencia que le proporcionaba su inmensa riqueza, hubiese presionado en el seno del linaje de Don Vela para que se admitiese en él a sus hijos, con objeto de así asegurarles una rápida carrera política ${ }^{44}$. En efecto, desde todos los puntos de vista la de Nicolao Beltrán de Ribera lo fue, ya que en un momento en que entre los caballeros hidalgos sorianos reinaba un gran descontento por las dificultades que planteaba el acceso al regimiento, debido al escaso número de oficios de regidores existente y a que éstos tendían a traspasarse de padres a hijos, un jovenzuelo recién llegado al linaje de Don Vela consiguió desplazar a otros muchos caballeros pertenecientes a familias de más rancio abolengo, accediendo a un selecto grupo de regidores del que entonces estaban todavía excluidas muy influyentes familias de la sociedad soriana, que tuvieron que esperar hasta la duplicación de oficios de 1543 para ver finalmente representados a sus miembros en el regimiento ${ }^{45}$.

No cabe duda de que la elección del linaje de Don Vela para llevar a su culminación su proyecto de integración en el núcleo del grupo oligárquico soriano no fue llevada a cabo por los Beltranes de forma aleatoria, sino que probablemente lo eligieron porque entonces en su seno no había figuras de gran relieve político o gran fortuna, abundando mucho más los simples hidalgos con modestos medios económicos y escasa influencia, y por ello les había de resultar mucho más fácil imponer en él su dominio ${ }^{46}$.

\footnotetext{
${ }^{43} \mathrm{Su}$ partida de bautismo se conserva en el libro de baustismos de la antigua parroquia de San Esteban, hoy custodiado en el Archivo de la iglesia parroquial del Espino de Soria. También hay referencias a ella en AHN, OOMM, Calatrava, exp. 2864. En 1540, cuando tendría 23 años, ya se le identifica como regidor.

${ }^{44}$ Tomamos la noticia de AHN, OOMM, Calatrava, exp. 2864.

${ }^{45}$ M. DiaGo, «Caballeros y ganaderos», págs. 492-494.

${ }^{46}$ La familia más influyente del linaje por esta época sería la de los Díaz de Caravantes, que había estado representada en el regimiento por dos individuos en la primera mitad del siglo XVI. En concreto, García Ruiz de Caravantes accedió en 1501 por el linaje de Don Vela, al morir el licenciado Andrés Calderón, que había sido regidor por el linaje de San Llorente, que se turnaba con el de Don Vela en la provisión de regidores. En 1513 García Ruiz cedió su regimiento a su sobrino Pedro Díaz de Caravantes. Ya entonces era una familia sin mucha riqueza e influencia, que consiguió acceder al regimiento aprovechando que el licenciado Andrés Calderón,
} 
El arrollador avance político de los Beltranes en la Soria de mediados del siglo XVI tuvo por otro lado su traducción en el hecho singular de que no sólo el primogénito Nicolao accedió al regimiento, sino también años después su hermano menor Antonio Beltrán de Ribera, a quien Felipe II hizo merced de un oficio de regidor acrecentado en 1558, la cual fue admitida sin inconvenientes en el ayuntamiento de Soria en contra de lo que solía ser habitual, puesto que el consistorio soriano casi siempre se resistió a tolerar que el rey de forma unilateral acrecentase el número de oficios de regidor ${ }^{47}$. Ciertamente en la segunda mitad del siglo XVI además de los Beltranes hubo alguna otra familia, como por ejemplo la de los Ríos, que consiguió tener al mismo tiempo más de un representante en el gobierno de la ciudad de Soria, puesto que la práctica de venta de oficios por la monarquía, que se intensificó en esta época, favorecía esta situación. Pero hay que tener en cuenta que a mediados de siglo la influencia política de los Beltranes en Soria estaba asegurada no sólo gracias a la presencia de los dos hermanos, Nicolao y Antonio, en el regimiento, sino también por el hecho de que un tercer hermano, Francisco Beltrán de Ribera, era deán de Soria y por lo tanto una de las dignidades eclesiásticas más influyentes de la ciudad.

\section{EL PROGRESIVO APARTAMIENTO DE LOS NEGOCIOS}

El acceso de los Beltranes al regimiento soriano marcó el inicio del proceso de su total conversión en una familia de nobles rentistas, escasamente preocupada por participar en negocios especulativos, que tan del gusto habían sido de Nicolao Beltrán y de su hijo Antonio Beltrán, los primeros representantes judeoconversos de la familia que todavía habían vivido sus primeros años como judíos.

individuo de gran relevancia política por su estrecha relación con los Reyes Católicos, murió sin hijos y dejó por consiguiente al linaje San Llorente desprovisto de personas influyentes. Para más detalles vid. M. DIAGO, Estructuras de poder en Soria, pág. 276.

${ }^{47} \mathrm{La}$ merced del oficio de regidor fue presentada en reunión del ayuntamiento de Soria el 26 marzo 1558, según consta por los libros de actas. Sobre la actitud del regimiento soriano ante los acrecentamientos de oficios decididos por el rey en los siglos XVI y XVII trata brevemente M. ${ }^{a}$ A. SOBALER SECO, "La oligarquía local soriana en el marco institucional de los Doce Linajes (Siglos XVI y XVII)", Arevacon 18 (1994) 29-36, 34-35. 
A Nicolao Beltrán de Ribera, el primero de la familia que accedió al oficio de regidor, todavía le encontramos en cierta medida vinculado con el tradicional negocio familiar del comercio de lanas, pero sólo en calidad de socio capitalista que invirtió en ocasiones fuertes cantidades de dinero en compañías establecidas con el dinámico mercader soriano Juan García de Tardajos, presumiblemente también judeoconverso, que era quien se encargaba de realizar el trabajo propiamente mercantil ${ }^{48}$.

Por lo demás no disponemos de muchas noticias sobre la trayectoria vital de este individuo, a quien quizás nuevos hallazgos documentales nos permitan conocer mejor en el futuro. Por el momento, no obstante, un hecho importante que conviene tener en cuenta para definir con más precisión su perfil es el de la concertación del matrimonio de su primogénita María Beltrán con el caballero de origen alemán Jerónimo Valter Zapata, bien conocido por sus actividades en Flandes en los últimos años del siglo XVI y primeros del XVII ${ }^{49}$.

De hecho nos ha resultado muy difícil llegar a comprobar documentalmente la existencia de este matrimonio, dado que en la mayor parte de las fuentes que proporcionan datos sobre la figura de Jerónimo Valter Zapata sólo se hacen referencias a su segundo matrimonio, sin indicar siquiera que había estado casado anteriormente, y no se indica que había pasado algunos años de su vida, al menos durante la década de 1580 , en la ciudad de Soria ${ }^{\text {so. }}$. Por otra

\footnotetext{
${ }^{48}$ Véase, por ejemplo, AHPS, PN, C. 32-83, Soria 22 marzo 1570. Allí se da cuenta de que Nicolao Beltrán de Ribera y Juan García de Tardajos el mayor habían constituido una compañía el 9 sept. 1564 , en la que el primero invirtió $150.000 \mathrm{mrs}$. y el segundo 75.000. Consta por otras fuentes documentales que el dinero de esta compañía se había empleado en compra de lanas, sobre todo a medianos propietarios ganaderos de aldeas serranas. Véase también AHPS, PN, C. 85-191, fol. 35, Soria 5 febr. 1584. Ana de Ribera, hija de Nicolao Beltrán de Ribera, reconoce haber recibido de Juan García de Tardajos 21.600 reales que se le debían por los siguientes conceptos: 20.000 de resto de 40.000 reales que su padre había puesto en una compañía; y 1.600 reales de las ganancias que había producido la compañía hasta fin de 1583, en que expiró.

${ }^{49}$ G. PARKer, El ejército de Flandes y el Camino Español 1567-1659, Madrid 1991, págs. 147 y 334 , da cuenta de su actividad como pagador general del ejército de Flandes entre 1595 y 1600; veedor general del ejército de Flandes entre 1600 y 1603, y mayordomo mayor de los archiduques entre 1602 y 1606 . Pueden verse noticias inéditas sobre este individuo y sus orígenes familiares en su expediente de entrada en la Orden de Santiago en 1594 en AHN, OOMM, Santiago, exp. 9019.

${ }^{50}$ Además de las referencias documentales citadas en la nota anterior conviene tener en cuenta para seguir la trayectoria de Jerónimo Valter Zapata a partir de la
} 
parte en las genealogías de la familia Beltrán no suele aparecer mencionada la hija primogénita de Nicolao Beltrán de Ribera, que en los protocolos notariales hemos podido comprobar que unas veces era identificada como María y otras como Ana, nombre este segundo que en las genealogías y en la mayor parte de los documentos se reserva para su segunda hija, casada con el noble vecino de Calatayud, Juan Zapata.

Este hecho se explica porque la primogénita no tuvo al parecer descendencia de su matrimonio con Jerónimo Valter Zapata y por eso dejó menos huella en las genealogías, al tiempo que el hecho de que unas veces se le llamase María y otras Ana ha contribuido decisivamente a que se la confundiese con su hermana menor ${ }^{51}$. La lectura detenida de varios documentos de los protocolos notariales de Soria de los últimos años de la década de 1580 nos ha demostrado sin embargo que Nicolao Beltrán de Ribera dejó como sucesora de su mayorazgo, en el que ocupaba un lugar principal el señorío de la villa de Tejado, a su hija mayor casada con Jerónimo Valter Zapata, quien es identificado en varios documentos como señor de Tejado ${ }^{52}$. Dado que este matrimonio no tuvo hijos, Jerónimo Valter Zapata, a la muerte de su esposa, que tendría lugar antes de 1588, pasaría a vivir a Madrid, su ciudad natal, mientras que los señoríos y tierras del mayorazgo de los Beltranes quedaban en manos de la segunda hija de Nicolao Beltrán de Ribera, casada con el caballero aragonés Juan Zapata, quien, pese a la coincidencia en el apellido, no era pariente de su cuñado Jerónimo Valter ${ }^{53}$.

década de 1590 el expediente de entrada en la Orden de Santiago de su hijo Lope Zapata Valter, habido de su segundo matrimonio con doña Francisca Velázquez, natural de México. AHN, OOMM, Santiago, 9120.

${ }_{51}$ En la genealogía relativamente completa de la familia Beltrán que figura en AHN, OOMM, Calatrava, exp. 2864, no hay ninguna mención a la primogénita de Nicolao Beltrán de Ribera. Sobre la confusión de nombres entre María y Ana vid. infra nota 52.

52 La mayor parte de los documentos notariales consultados en que Jerónimo Valter Zapata aparece como señor de Tejado corresponden a los años 1584 y 1585. En un documento datado en Soria, 8 abril 1588, Jerónimo Valter Zapata aparece ya identificado como vecino de Madrid y heredero universal de Ana Beltrán de Ribera (AHPS, PN, C. 88-197, fol. 135). No hay duda de que se refiere a la primogénita, también llamada María, porque en escrituras posteriores a esta fecha aparece otra Ana Beltrán de Ribera, la segunda hija de Nicolao, casada con Juan Zapata, heredera del mayorazgo familiar a la muerte de su hermana mayor y, como tal, señora de Tejado.

${ }^{53}$ Hay que hacer notar no obstante que los Zapata de Calatayud sí estaban lejanamente emparentados con los Zapata de Madrid, de quienes era pariente Jerónimo Valter a través de su madre. 
La concertación de un matrimonio entre vecinos de Soria y de Madrid representa un hecho insólito tanto en el contexto del siglo XV como en el del XVI; pero además el de Jerónimo Valter Zapata con María Beltrán de Ribera presentó la peculiaridad de que el primero era un individuo de origen alemán, más concretamente suabo, hijo de un factor de la compañía de los Fugger en España, Justo Valter ${ }^{54}$. Cómo entró en contacto un regidor judeoconverso soriano, hijo de un activo mercader que había tenido negocios en Flandes y en las propias ferias de Medina del Campo, con un factor de una compañía financiera y mercantil alemana, estrechamente vinculada con la dinastía de los Habsburgo, para concertar el matrimonio de sus hijos, es algo que no hemos podido llegar a determinar. Pero la simple constatación del hecho del matrimonio nos invita a presumir que todavía la tercera generación de los Beltranes se movió en el mundo de los grandes hombres de negocios de Castilla a través de unas vías que no obstante convendría determinar con mayor precisión.

Por lo demás, si el matrimonio de María Beltrán prueba la persistencia de ciertas vinculaciones con el mundo de los negocios, el de su hermana menor Ana con el caballero bilbilitano Juan Zapata testimonia de forma rotunda el deseo de los Beltranes de incorporarse definitivamente a la nobleza castellana,y de preparar el camino a la entradȧ en las órdenes militares ${ }^{55}$. En efecto, la desvinculación de Ana Beltrán de Ribera y su marido Juan Zapata de los negocios mercantiles y financieros parece que fue total, a juzgar por las noticias de que disponemos. En sus inventarios de bienes y en los de sus descendientes ya no se encuentran partidas en las que aparezcan como acreedores o deudores de grandes mercaderes u otros hombres de negocios, mientras que en contrapartida abundan

\footnotetext{
54 Según declaraciones de testigos tomadas en 1594; véase AHN, OOMM, Santiago, exp. 9019.

55 El hermano de Juan Zapata, Manuel Zapata, fue por ejemplo cabaliero de Santiago y gentilhombre de la boca del rey. No cabe duda de que estos antecedentes familiares favorecieron la entrada en la Orden de Calatrava del nieto de Ana Beltrán de Ribera y Juan Zapata, Juan Francisco Zapata, heredero del mayorazgo, señor de Tejado y regidor de Soria. Puede verse su expediente de entrada, muy voluminoso porque se presentó una denuncia sobre el origen converso de los Beltranes, en AHN, OOMM, Calatrava, exp. 2864. Llama la atención que todavía en la actualidad algunos investigadores rechazan como infundada esta denuncia, cuando tantas pruebas documentales demuestran el origen converso de Nicolao Beltrán. Véase, por ejemplo, V. Dávila Jalón, Nobiliario de Soria, Madrid 1967, págs. 193 y ss.
} 
las referencias a rentas en cereal y juros de la monarquía ${ }^{56}$. Al mismo tiempo estos representantes de la familia en las postreras décadas del XVI y primeras del XVII aparecen absolutamente desvinculados de una de las actividades más florecientes en el ámbito soriano del momento, la de la ganadería trashumante. En los protocolos notariales sólo se encuentran referencias a su condición de propietarios de un pequeño rebaño de ganado estante, que, por producir lanas de inferior calidad a las de los trashumantes, no les pudo permitir entrar en el negocio de la venta de lanas para exportación, el cual aseguró saneados ingresos a otros representantes de la oligarquía soriana en esos siglos ${ }^{57}$.

Los descendientes del judío Vicen Bienveniste, que ya a fines del siglo XVI llevaban con orgullo sonoros apellidos de nobleza aragonesa, como Palafox o Zapata, y por entonces comenzaron también a emparentar con caballeros de las Órdenes Militares para poco después ingresar ellos mismos en éstas, terminaron perdiendo su espíritu emprendedor, pasando a apegarse de una forma casi obsesiva a la tierra. Renunciaron de esta manera a seguir acumulando riquezas al ritmo que lo habían hecho sus antepasados, conformándose con la percepción regular de unas rentas que les permitirían llevar una vida desahogada y ociosa, aunque quizás no resultasen suficientes para satisfacer sus ambiciones de ostentación.

\footnotetext{
56 Véase el inventario de bienes a la muerte de Juan Zapata, viudo de Ana Beltrán de Ribera en Soria 27 enero 1604, en AHPS, PN, C. 98-219, fol. 167. Abundan las referencias a juros y censos, muchos de ellos heredados de sus antepasados. El inventario de bienes a la muerte del primogénito del anterior, Don Juan Zapata Beltrán y Palafox, realizado en Soria 8 sept. 1633, figura en AHPS, PN, C. 459-799, fol. 356. Se advierte que no había incrementado apenas los bienes heredados de sus antepasados, e incluso que su hacienda había venido a menos por falta de atención. Consta que gestionaba directamente la explotación de una parte de sus tierras, de la que obtuvo una cosecha de unas 2.000 fanegas, y que el resto las cedía a renteros, que le entregaron en renta unas 700 fanegas.

57 En 1610, por ejemplo, Juan Zapata Beltrán, señor de Tejado, aparece como vendedor de 50 arrobas de lana churra procedente de su ganado, que entregaría a un mercader de Soria en el lugar de Ledesma, donde él tenía extensas propiedades en tierras (AHPS, PN, C. 104-230, fol. 345, Soria 17 nov. 1610). En 1608 otro representante de la familia, Antonio Beltrán de Ribera Morales de Albornoz, regidor de Soria y señor de Malluembre, tío y a la vez suegro del anterior, aparece vendiendo 338 arrobas de lana churra (AHPS, PN, C. 102-227, fol. 528, Soria 31 oct. 1608). La lana churra, procedente del esquile del ganado estante, alcanzaba en el mercado precios muy inferiores a los de la llamada lana extremeña, la procedente de los ganados trashumantes.
} 
Cabe preguntarse no obstante si en todo esto hubo una traición de ideales «burgueses», o por el contrario una percepción clarividente de las dificultades que para la realización de negocios especulativos se estaban planteando en el reino de Castilla ya en la segunda mitad del siglo XVI, que habría llevado a una "retirada a tiempo". No es fácil decidirse por una u otra alternativa, pero no cabe duda que la falta de espíritu emprendedor manifestada por los Beltranes a partir de la cuarta generación impidió a esta familia auparse a los primeros puestos en el seno del grupo oligárquico soriano, de manera que el proceso de su ascenso social, que fue muy rápido en la primera mitad del siglo XVI, terminó viéndose desbordado por el de otras familias que apostaron más decididamente por la ganadería trashumante, compatibilizada por supuesto con las inversiones en señoríos, tierras y juros.

En cualquier caso la integración dentro del grupo social dominante en el marco urbano de estos judeoconversos fue plena y no llegó en ningún momento a resultar seriamente cuestionada, aunque nunca faltasen denuncias aisladas de su posible origen judío, que en todas las ocasiones fueron convenientemente acalladas. Y finalmente los descendientes de Vicen Bienveniste llegaron a convertirse en marqueses de La Vilueña, accediendo por consiguiente incluso a la nobleza titulada, si bien en un momento en que el reconocimiento social de la pertenencia a este grupo era ya considerablemente menor debido a la multiplicación del número de títulos. Pero al análisis de esta fase de la historia de la familia prestaremos atención en otro momento.

$\begin{array}{ll}\text { ABREVIATURAS } \\ \text { AChV } & \text { Archivo de la Chancillería de Valladolid } \\ \text { AGS } & \text { Archivo General de Simancas } \\ \text { AHN } & \text { Archivo Histórico Nacional } \\ \text { AHPS } & \text { Archivo Histórico Provincial de Soria } \\ \text { C. } & \text { Caja } \\ \text { EMR } & \text { Escribanía Mayor de Rentas } \\ \text { F. } & \text { Fenecidos } \\ \text { OOMM } & \text { Órdenes Militares } \\ \text { P.C. } & \text { Pleitos Civiles } \\ \text { PN } & \text { Protocolos Notariales } \\ \text { RAH } & \text { Real Academia de la Historia } \\ \text { RE } & \text { Reales Ejecutorias } \\ \text { RGS } & \text { Registro General del Sello. }\end{array}$




\section{RESUMEN}

Se analiza el proceso de integración y ascenso social y político de la familia de un judío soriano convertido al cristianismo después de un breve exilio en Portugal en 1492. Se sigue la trayectoria de cuatro generaciones de esta familia, dando cuenta, entre otros aspectos, de las actividades económicas desempeñadas por sus distintos miembros, de sus actitudes hacia la religión cristiana, y de su política de concertación de matrimonios. Se demuestra que su incorporación al grupo oligárquico soriano fue temprana y vino facilitada por su rápido enriquecimiento durante la primera mitad del siglo XVI. Finalmente se advierte cómo asumieron pronto los ideales y el modo de vida de la nobleza castellana, realizando importantes inversiones en compras de tierras y señoríos.

\section{SUMMARY}

The author analyses the process of integration and social promotion of a converso family from the Castilian town of Soria, whose members adhered to the Christian faith after a short exile in Portugal in 1492. He presents the evolution of four generations of that family concerning their economic activities, their attitudes towards the Christian religion, and their political views on marriage. He proves that the Beltrán family reached very soon a high position among the oligarchy of Soria, position that was easily attained because of the increasing economic power of that family during the first half of the sixteenth century. Finally he shows how the family also assumed very quickly the ideals and the way of life of the Castilian nobility, and made investments of large amounts of money in buying lands and lordships. 